ISSN 25980580

Bioscientia Medicina Volume 3, Issue 1, Page No: 38-50

Available online : www.bioscmed.com

Bio Sc Med 3(1) :38-50

\title{
SLEEP AND BONE DENSITY: A STUDY ON POSTMENOPAUSAL INDONESIAN WOMEN
}

\author{
Shafira Irmayati ${ }^{1}$, Muhammad Reagan ${ }^{2}$, Legiran $^{3}$
}

${ }^{1}$ Undergraduate Student, Faculty of Medicine, Universitas Sriwijaya

${ }^{2}$ Department of Internal Medicine, Faculty of Medicine, Universitas Sriwijaya

${ }^{3}$ Department of Anatomy, Faculty of Medicine, Universitas Sriwijaya

*Corresponding Author E-mail: shafirairmayanti@gmail.com

Received : November $24^{\text {th }} 2018$

Accepted :February $4^{\text {th }} 2019$

\begin{abstract}
Background: Low bone density has been known as one of the factors that increased fracture risk. Aging, estrogen deficiency, low BMI, and inadequate calcium intake are known factors that contribute to decreased bone density. Other than the known factors, some research show that sleep duration can also lower bone density. Sleep affects bone density in a way that it causes increased level of cortisol, proinflammatory cytokine, and decreased in physical activity.

Method: This study is an observational analytic study with cross-sectional design. It is conducted on menopausal patients that has been examined with bone mineral densitometry at Rheumatology Outpatient General Hospital Dr. Mohammad Hoesin Palembang in November 2017 to Oktober 2018. Samples are collected using total sampling technique.

Results: From 93 subjects that participated in this study, 20,4\% of them had osteopenia, and 51,6\% had osteoporosis. Patients with low bone density, mainly slept for 6 to 8 hours at night per day, 30 minutes of nap per day, and has a total sleep duration for less than 8 hours each day. This study shows no significant association between night-time sleep, daytime napping, and total sleep duration with bone density ( $p$ value $=0,168, p$ value $=0,831, p$ value $=0,984)$. Analysis on other risk factors show significant association between body mass index and low bone density ( $\mathrm{p}$ value $=0,002$ ).

Conclusion: There are no significant association between sleep duration and bone density in menopausal patients.
\end{abstract}

Keywords: Sleep duration, bone density, menopause 


\section{ISSN 25980580}

\section{Background}

Bone strength and risk of fracture are strongly related to bone density. Research shows that a continuous and progressive decrease in bone density causes an increased risk of fracture ${ }^{1}$. The World Health Organization in 1994 made the value of bone density a reference in the diagnosis of osteoporosis $^{2}$. Osteoporosis is a disorder of the bones, which is characterized by reduced bone mass density and damage to micro-structural tissue of bone, causing vulnerability for bones to experience fractures $^{3}$. It is estimated that every year there are 9 million cases of fractures due to osteoporosis. This number will increase three to four times in $2050^{4}$. The results of studies in Indonesia also show that osteoporosis can occur in both women and men, with a comparison of the prevalence of women 4 times higher than men ${ }^{5}$.

Aging, estrogen deficiency, low body mass index, and lack of calcium consumption are commonly known risk factors of decreased bone density ${ }^{6}$. Nutrition, physical activity, and lifestyle also have a role in maintaining bone health ${ }^{7}$. Decreasing estrogen levels or estrogen deficiency is most commonly found in menopausal women. In situations where estrogen levels are lacking, osteoblasts will experience a shortened life span, while osteoclasts will experience increased lifespan and activity resulting in an imbalance between bone formation and resorption ${ }^{8}$.

Besides the above factors, the results of the study show that there are other factors that influence the decrease in bone density, namely the duration of sleep ${ }^{3}$. Research on the relationship of sleep duration and bone density has varied results. Decreased bone density due to poor sleep duration is thought to be caused by increased cortisol and increased pro-inflammatory response activity ${ }^{9,10}$. Conversely, long sleep conditions, will cause low physical activity and decrease sun exposure so that it decreases bone density ${ }^{6,11}$.

Since similar research is still very limited in Indonesia, this research is expected to be a preliminary study related to the relationship between sleep duration and bone density in menopausal patients in the Internal Medicine Rheumatology Clinic Dr. RSUP Mohammad Hoesin Palembang.

\section{Methods}

This study is an observational analytic study with cross sectional design. In this study postmenopausal female patients who first underwent bone density examination in Rheumatology Outpatient General Hospital Dr. Mohammad Hoesin Palembang in the period November 2017 October 2018 were included as subject. Sampling was carried out using total sampling techniques; 


\section{ISSN 25980580}

the minimum sample size needed was 49 respondents. The variables examined in this study were bone density as a dependent variable, sleep duration as an independent variable, and confounding variables consisting of BMI, comorbid factors, sun exposure, frequency of outdoor activity, sun protection, and physical activity.

The data collected consists of primary data that were obtained by conducting structured interviews. While secondary data obtained through observation of patient medical record data. Primary data includes sleep duration, duration of sun exposure, frequency of outdoor activities, the use of sun protection, physical activity, work, and comorbidities. Secondary data consists of identity, bone density, and BMI. Univariate analysis was conducted to determine frequency distribution based on the characteristics of the study. Bivariate analysis using the Chi-Square test was conducted to determine the relationship between variables.

\section{Results}

By applying the total sampling method to the population that fulfills the participation criteria, a sample of 93 people is obtained. Table 1 shows that the majority of respondents worked as housewives, namely 81 people $(87.1 \%)$, from the table it was also found that more than half of the respondents were over 65 years old $(51.6 \%)$.

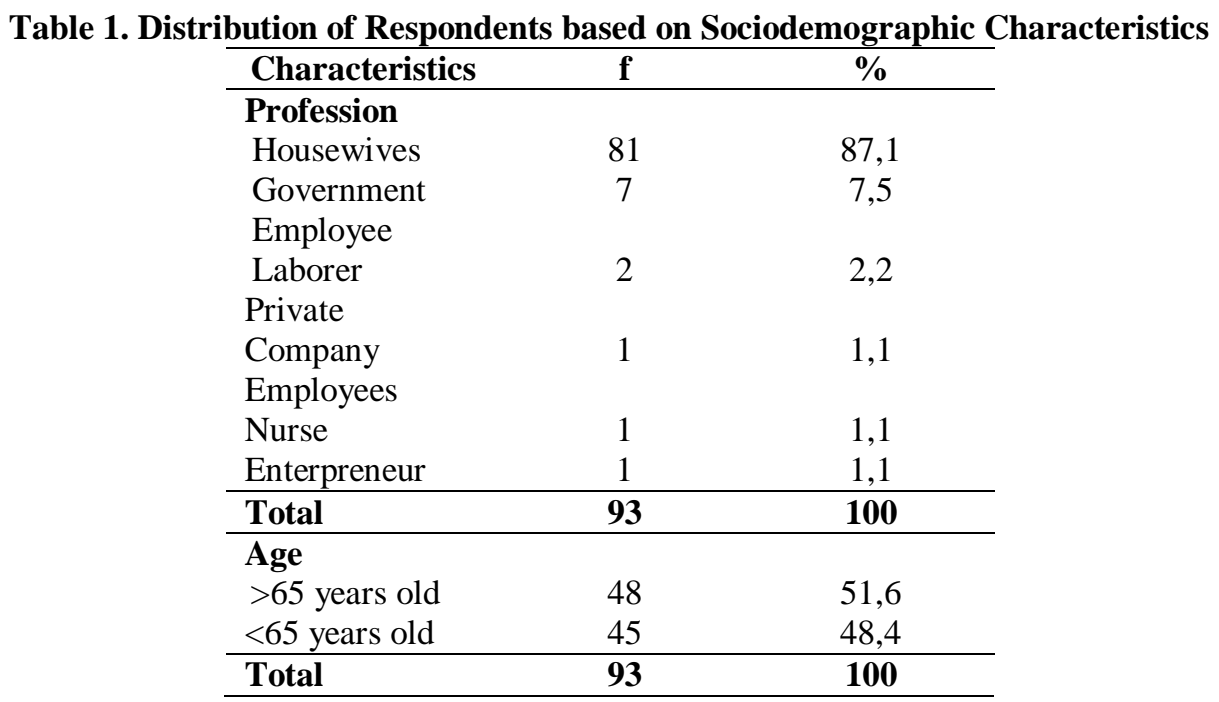

In table 2, it can be seen that more than half of the respondents slept at night for 6-8 hours, as many as 48 people $(51.6 \%)$. In addition, based on the categorization of nap duration, respondents who took naps more than 60 minutes were at least 16 people $(17.2 \%)$, while most of the other 


\section{ISSN 25980580}

respondents took naps for 30 minutes $(33.3 \%)$. Research on total sleep duration shows that, more than half of the respondents only slept for less than 8 hours per day, as many as 53 people (57\%).

Table 2. Distribution of Respondents based on Sleep Duration

\begin{tabular}{lll}
\hline \multicolumn{1}{c}{ Characteristics } & f & \% \\
\hline $\begin{array}{l}\text { Night Time Sleep } \\
\text { Duration } \\
<6 \text { hours }\end{array}$ & \\
6-8 hours & 22 & 23,7 \\
$\geq 8$ hours & 48 & 51,6 \\
\hline Total & 23 & 24,7 \\
\hline Nap Duration & $\mathbf{9 3}$ & $\mathbf{1 0 0}$ \\
0 minute & & \\
$>0-30$ minutes & 19 & 20,4 \\
$>$ 30-60 minutes & 31 & 33,3 \\
$>$ 60 minutes & 27 & 29,0 \\
\hline Total & 16 & 17,2 \\
\hline Total Sleep Duration & $\mathbf{9 3}$ & $\mathbf{1 0 0}$ \\
$<8$ hours & & \\
8-9 hours & 53 & 57,0 \\
$\geq 9$ hours & 21 & 22,6 \\
\hline Total & 19 & 20,4 \\
\hline
\end{tabular}

The results of the research presented in table 3 show that the majority of respondents experienced a decrease in bone density as many as 48 people (51.6\%) with osteoporosis, and 19 people (20.4\%) with osteopenia. The results also shows that of the total respondents only 20 people $(21.5 \%)$ had normal BMI, as many as 14 people (15.1\%) other respondents had less BMI, and others had excessive BMI. In the table it can be seen that more than half of the respondents spent half an hour or more doing outdoor activities, while 46 people (49.5\%) other respondents only spent a short time or almost never doing outdoor activities.

Respondents who reported never having activities outside the room were respondents who were aged or had severe osteoporosis so they were no longer able to carry out outdoor activities for long periods of time. Respondents who spent more than half an hour or more reported doing activities such as gardening, sweeping the yard, or just sitting on the lawn. A total of 47 people (50.5\%) respondents had outdoor activities for less than 4 times a week. Based on the results of the study, 71 people $(76.3 \%)$ respondents used sun protection in the form of a veil when doing outdoor activities.

The research data also shows that the majority of respondents in their daily activities carry out mild physical activity as many as 77 people $(82.8 \%)$, and only as many as $2.1 \%$ of respondents do heavy physical activity in their daily lives. In the study it was found that a small proportion of respondents had concomitant diseases such as type 2 diabetes mellitus. 


\section{ISSN 25980580}

Table 3. Distribution of Respondents based on Bone Density and Confounding Factors

\begin{tabular}{|c|c|c|}
\hline Characteristics & $\mathbf{f}$ & $\%$ \\
\hline \multicolumn{3}{|l|}{ Bone Density } \\
\hline Normal & 26 & 28,0 \\
\hline Osteopenia & 19 & 20,4 \\
\hline Osteoporosis & 48 & 51,6 \\
\hline Total & 93 & 100 \\
\hline \multicolumn{3}{|l|}{ BMI } \\
\hline Underweight & 14 & 15,1 \\
\hline Normal & 20 & 21,5 \\
\hline Overweight & 10 & 10,8 \\
\hline Obesity & 49 & 52,7 \\
\hline Total & 93 & 100 \\
\hline \multicolumn{3}{|l|}{$\begin{array}{ll}\text { Sunlight } & \text { Exposure }\end{array}$} \\
\hline \multicolumn{3}{|l|}{ Duration } \\
\hline$<30$ minutes & 46 & 49,5 \\
\hline$\geq 30$ minutes & 47 & 50,5 \\
\hline Total & 93 & 100 \\
\hline \multicolumn{3}{|l|}{ Outdoor Activities } \\
\hline \multicolumn{3}{|l|}{ Frequency } \\
\hline $1-3 x /$ week & 47 & 50,5 \\
\hline$>3 x /$ week & 46 & 49,5 \\
\hline Total & 93 & 100 \\
\hline \multicolumn{3}{|l|}{ Sunlight Protection } \\
\hline Yes & 71 & 76,3 \\
\hline No & 22 & 23,7 \\
\hline Total & 93 & 100 \\
\hline \multicolumn{3}{|l|}{ Physical Activities } \\
\hline Mild & 77 & 82,8 \\
\hline Moderate & 14 & 15,1 \\
\hline Heavy & 2 & 2,1 \\
\hline Total & 93 & 100 \\
\hline \multicolumn{3}{|l|}{ Comorbid Factor } \\
\hline No & 81 & 87,1 \\
\hline Yes & 12 & 12,9 \\
\hline Total & 93 & 100 \\
\hline
\end{tabular}

Table 4 shows that based on the results of the Chi-square statistic between night sleep duration and bone density $\mathrm{p}$ value is 0.168 with a $\mathrm{p}$ value $<0.05(5 \%)$ which means there is no statistically relationship between night sleep duration and bone density. The same analysis was also conducted to analyze the relationship between nap duration and bone density, and produce a $\mathrm{p}$ value of 0.831 , which means there is no statistically relationship between the two variables. Chi-square statistical test was performed on the analysis of the relationship between total sleep duration and bone density and getting a $\mathrm{p}$ value of 0.984 with a $\mathrm{p}$ value $<0.05(5 \%)$ which means there was no statistically relationship between total sleep duration and bone density. 
ISSN 25980580

Table 4. Relationship of Sleep Duration with Bone Density

\begin{tabular}{|c|c|c|c|c|}
\hline \multirow{2}{*}{ Characteristics } & \multicolumn{2}{|c|}{ Bone Density } & \multirow{2}{*}{ Total } & \multirow{2}{*}{$p$ value } \\
\hline & Abnormal & Normal & & \\
\hline Night Time Sleep Duration & & & & 0.168 \\
\hline$<6$ hours & 14 & 8 & 22 & \\
\hline$\geq 8$ hours & 20 & 3 & 23 & \\
\hline 6-8 hours & 33 & 15 & 48 & \\
\hline Total & 67 & 26 & 93 & \\
\hline Nap Duration & & & & 0.831 \\
\hline$>60$ minutes & 10 & 6 & 16 & \\
\hline$>30-60$ minutes & 20 & 7 & 27 & \\
\hline$>0-30$ minutes & 23 & 8 & 31 & \\
\hline 0 minutes & 14 & 5 & 19 & \\
\hline Total & 67 & 26 & 93 & \\
\hline Total Sleep Duration & & & & 0.984 \\
\hline$\geq 9$ hours & 14 & 5 & 19 & \\
\hline $8-9$ hours & 15 & 6 & 21 & \\
\hline$<8$ hours & 38 & 15 & 53 & \\
\hline Total & 67 & 26 & 93 & \\
\hline
\end{tabular}

Table 5 shows that based on the results of the Chi-square statistical test, among the six confounding factors analyzed, the factor that has a statistically significant relationship with bone density is the body mass index, the BMI factor obtained $p$ value of 0.002 with a value of $p<0.05$ ( $5 \%)$. Other confounding factors were not statistically significant for bone density. 
ISSN 25980580

Table 5. Relationship of Confounding Factors with Bone Density

\begin{tabular}{|c|c|c|c|c|}
\hline \multirow{2}{*}{ Characteristics } & \multicolumn{2}{|c|}{ Bone Density } & \multirow{2}{*}{ Total } & \multirow{2}{*}{$p$ value } \\
\hline & Abnormal & Normal & & \\
\hline BMI & & & & $0.002 *$ \\
\hline Underweight & 13 & 1 & 14 & \\
\hline Normal & 18 & 2 & 20 & \\
\hline Overweight & 9 & 1 & 10 & \\
\hline Obesitas & 27 & 22 & 49 & \\
\hline Total & 67 & 26 & 93 & \\
\hline Comorbid Factor & & & & 0.088 \\
\hline Yes & 6 & 6 & 12 & \\
\hline No & 61 & 20 & 81 & \\
\hline Total & 67 & 26 & 93 & \\
\hline Sunlight Exposure Duration & & & & 0.767 \\
\hline$<30$ minutes & 32 & 14 & 46 & \\
\hline$\geq 30$ minutes & 35 & 12 & 47 & \\
\hline Total & 67 & 26 & 93 & \\
\hline Outdoor Activities Frequency & & & & 0.767 \\
\hline $1-3 x /$ week & 35 & 12 & 47 & \\
\hline$>3 \mathrm{x} /$ week & 32 & 14 & 46 & \\
\hline Total & 67 & 26 & 93 & \\
\hline Sunlight Protection & & & & 0.463 \\
\hline Ya & 53 & 18 & 71 & \\
\hline Tidak & 14 & 8 & 22 & \\
\hline Total & 67 & 26 & 93 & \\
\hline Physical Activities & & & & 0.296 \\
\hline Mild & 58 & 19 & 77 & \\
\hline Moderate & 8 & 6 & 14 & \\
\hline Heavy & 1 & 1 & 2 & \\
\hline Total & 67 & 26 & 93 & \\
\hline
\end{tabular}

\section{Discussions}

This study found that the majority of female patients who had undergone menopause had a sleep duration of 6 to 8 hours per night which was 48 people (51.6\%), followed by patients with a duration of more than 8 hours as many as 23 people $(24.7 \%)$ and patients with sleep duration of less than 6 hours was 22 people $(23.7 \%)$. These results are similar with previous studies which found that female patients who slept 6 to 8 hours per night as much as $40 \%$ of the total sample, patients who slept less than 6 hours as much as $29 \%$, and patients who slept more than 8 hours as many as $33 \%$ 3 . The results also showed that menopausal patients routinely take a nap each day, out of all 93 study respondents there were 74 people $(79.6 \%)$ who sleep during the day, 19 other people $(20.4 \%)$ reported that never slept during the day. The results obtained in previous studies also show that $71.3 \%$ of menopausal women have a nap habit ${ }^{12}$. According to Milner and Cote this happen because older individuals tend to easily drowsy, and have plenty of time to sleep during the day after retirement ${ }^{13}$. 
Total sleep duration is obtained by summing the patient's sleep duration at night and during the day. In this study, 53 patients (57\%) slept for less than 8 hours per day, 21 people $(22.6 \%)$ slept eight to 9 hours per day and 19 people (20.4\%) slept for more than 9 hours per day. Differences in the distribution of patients based on total sleep duration can be found in previous studies which found that most patients $(41.8 \%)$, slept for eight to 9 hours per day ${ }^{11}$. This study found that menopausal women who had normal bone density were only $28 \%$ of the total subject. Previous research on menopausal women also showed similar things, namely, only $31.3 \%$ of menopausal women had normal bone density ${ }^{12}$. This can be caused because after menopause there will be major decreased in estrogen levels, causing an increase in the process of bone resorption and a decrease in bone formation which results in a decrease in bone density ${ }^{8}$.

The results of this study indicate that the majority of respondents have outdoor activity one to three times a week, by spending more than 30 minutes, $76.3 \%$ of respondents use sun protection such as veil when doing outdoor activities. This result is similar to the previous studies, which found that the majority of respondents used sun protection when doing outdoor activities, most of the respondents also spent more than 30 minutes while doing outdoor activities but in more frequent frequencies which were more than three times a week ${ }^{14}$.

Based on research data more than half of the respondents had an excess body mass index of $52.7 \%$, and only $21.5 \%$ of respondents had a normal body mass index. As many as 77 people (82.8\%) respondents only did light activities in their daily lives, because most of the respondents were elderly and were unable to do heavy work. This study found that as many as 12 respondents had other comorbidities, type II DM, 82 other respondents did not have comorbidities associated with a decrease in bone density. Research conducted by Saetung et al. in 387 menopausal women, also showed that only a small proportion of the respondents were found to have diabetes (15.5\%) 12. The relationship analysis conducted in this study found that there was no relationship between sleep duration and bone density, both at night time sleep duration, nap duration, and total sleep duration. The results obtained in this study are different with some of the studies that have been done previously in Chinese women and in Puerto Rican men and women, who said that there was a relationship between sleep duration at night and bone density. Both studies show a relationship to short sleep duration and long sleep duration with bone density ${ }^{9,15}$. The mechanisms underlying the relationship between the two are, changes in osteoblasts and osteoclasts circadian rhythm, increased activity of pro-inflammatory cytokines, secretion of the hormone cortisol, and changes in growth 


\section{ISSN 25980580}

hormone metabolism, which are important regulators in the process of bone formation and resorption $^{16,17}$.

The chi-square statistical test conducted between nap duration and bone density showed a p value of 0.831 with a value of $\mathrm{p}<0.05(5 \%)$ which means there was no statistical relationship between the two. Other studies show different things about the relationship between nap duration and bone density. The study found that elongation of nap duration was directly proportional to the decrease in bone density value. The relationship between nap duration and a decrease in bone density values is associated with a decrease in physical activity in individuals who nap for a long time ${ }^{11}$. Analysis of total sleep duration with bone density using the chi-square statistical test showed that there was no statistically relationship between the two variables. In the results of this study, the $\mathrm{p}$ value obtained was 0.984 with a value of $\mathrm{p}<0.05(5 \%)$. The results of previous studies also found that there was no significant relationship between total sleep duration and a decrease in bone density ${ }^{18}$. In contrast, research conducted by Chen et al. showed a relationship between long total sleep duration and a decrease in bone density values, the relationship between the two is said to be a result of a decrease in physical activity in individuals who have longer sleep duration ${ }^{11}$.

No association between sleep duration and bone density can be caused by a significant difference in proportion between respondents with normal and abnormal bone density in all sleep duration categories, it can also indicate that the role of sleep duration is small compared to other factors in causing a decrease in bone density. In this study, it was found that there were other factors that were more influential in decreasing bone density, namely body mass index. One factor that is said to have a role in decreasing bone density is body mass index. In this study, body mass index proved to have a significant relationship to a decrease in bone density in female patients who experienced menopause. Previous research reported that obese women had higher bone density than women with normal body mass index, the relationship was found in women in the age group 55-75 years, and no similar relationship was found in women aged 25-45 years, so that It was concluded that a high body mass index could be a protective factor of a decrease in bone density caused by increasing age $^{19}$.

In this study an analysis of other factors that are thought to play an important role in maintaining bone density, namely vitamin $\mathrm{D}$, is described by the use of sun protection, frequency of sun exposure and prolonged exposure to sunlight. Based on the analysis conducted between the use of sun protection, frequency, and sun exposure to bone density, it was found that there was no significant relationship between the two. According to previous studies using sun protection, lack 


\section{ISSN 25980580}

of frequency and lack of sun exposure have an effect on decreasing vitamin D levels in the body ${ }^{14}$. No significant relationship can be obtained because the majority of respondents aged over 65 years, according to Gallagher in individuals aged 65 years of producing vitamin D in the skin will experience a decline. This condition is caused by a decrease in the concentration of 7dehydrocholesterol in the epidermis and a decrease in the response to UV light, resulting in a reduction of pre-vitamin D3 formation by $50 \%{ }^{20}$.

Physical activity has an important role in maintaining bone density, in previous studies it was found that in women with mild activity bone density will have a lower value than women who carry out more activity ${ }^{21}$. However this study found no association between mild activity and decreased bone density. Mcmillan said that physical activity would induce the effects of anabolism or homeostasis through a process of mechanical transduction in the bone. Movement of fluid in the extracellular matrix will exert strength on osteocytes and bone cells which will then trigger the release of NO and prostaglandins so that osteoprogenitor cells will differentiate into pre-osteoblasts. Pre-osteoblasts will then undergo maturation into osteoblasts so that new bone cell formation occurs $^{22}$. In this study an analysis of the relationship between the concomitant diseases of the respondents was also carried out, the comorbidities analyzed were type 2 diabetes mellitus. The results of the analysis showed that there was no significant association between comorbidities and decreased bone density. Research shows that patients suffering from type 2 diabetes mellitus tend to have higher bone density values, which can be caused because hyperinsulinemia conditions will cause activation of IGF-1 which is one factor in increasing bone density ${ }^{23,24}$.

The insignificant results in the analysis of confounding factors other than body mass index can be caused by considerable difference between patients with abnormal bone density and patients with normal bone density, especially in low risk categories, so that the relationship between variables is not statistically proved to be significantly related.

\section{Conclusions}

There is no relationship between total daily sleep duration and decreased bone density.

\section{Acknowledgements}

The author would like to thank dr. Muhammad Reagan, Sp.PD, M.Kes; Dr. dr. Legiran, M.Kes; dr. Surya Darma, Sp.PD; and dr. Safyudin, M.Biomed who provided input, assistance, criticism and 


\section{ISSN 25980580}

suggestions so that this research would be even better. Also thanks to the Medical Faculty of Sriwijaya University and all those who helped in the effort to carry out this research.

\section{References}

1. Setiyohadi B. Penyakit Skeletal. In: Buku Ajar Ilmu Penyakit Dalam Edisi VI Jilid III. Interna Publishing; 2014.

2. WHO. Assessment of fracture risk and its application to screening for postmenopausal osteoporosis: report of a WHO study group [meeting held in Rome from 22 to 25 June 1992]. 1994;

3. Martin M Saint, Labeix P, Garet M, ... TT-... of CS, 2016 undefined. Does subjective sleep affect bone mineral density in older people with minimal health disorders? The PROOF cohort. 2016;12(11).

4. Compston J. Osteoporosis: Social and Economic Impact. Radiol Clin North Am. 2010;48(3):47782.

5. Tirtarahardja G, Setyohadi B, Weynand LS, Zhu Q. Bone Mineral Density Reference Values for Indonesian Men and Women. J Bone Min Res. 2006;21 (Suppl.(March):S142.

6. Kim N, Choi H-R, Kim S-W, Kim B-S, Won C-W, Kim S-Y. Association between Bone Mineral Density and Sleep Duration in the Korean Elderly Population. Korean J Fam Med. 2014;35(2):90.

7. Ho SC, Chan SG, Yip YB, Chan CSY, Woo JLF, Sham A. Change in bone mineral density and its determinants in pre-and perimenopausal Chinese women: the Hong Kong perimenopausal women osteoporosis study. Osteoporos Int. 2008;19(12):1785-96.

8. Lindsay R, Cosman F. Osteoporosis. In: Harrison's Principles of Internal Medicine. 19th Editi. McGraw-Hill Education; 2015.

9. Fu X, Zhao X, Lu H, Jiang F, Ma X, Zhu S. Association between sleep duration and bone mineral density in Chinese women. Bone. 2011;49(5):1062-6.

10. Miller MA, Kandala N, Kivimaki M, Kumari M, Brunner EJ, Lowe GDO. Gender Differences in the Cross-Sectional Relationships Between Sleep Duration and Markers of Inflammation: Whitehall II Study. Sleep. 2009;2009.

11. Chen G, Chen L, Wen J, Yao J, Li L, Lin L, et al. Associations between sleep duration, daytime nap duration, and osteoporosis vary by sex, menopause, and sleep quality. J Clin Endocrinol Metab. 2014;99(8):2869-77.

12. Saetung S, Reutrakul S, Chailurkit LO, Rajatanavin R, Ongphiphadhanakul B, Nimitphong H. The Association between Daytime Napping Characteristics and Bone Mineral Density in Elderly Thai Women without Osteoporosis. Sci Rep. 2018;8(1):1-8.

13. Milner CE, Cote KA. Benefits of napping Benefits of napping in healthy adults : impact of nap length , time of day , age , and experience with napping. 2009;18:272-81.

14. Hidayat R, Setiati S, Soewondo P. The association between vitamin D deficiency and type 2 diabetes mellitus in elderly patients. Acta Med Indones. 2010;42(3):123-9.

15. Niu J, Sahni S, Liao S, Tucker KL, Dawson-hughes B. Association between Sleep Duration, Insomnia Symptoms and Bone Mineral Density in Older Boston Puerto Rican Adults. 2015;1-11.

16. Raggatt LJ, Partridge NC. Cellular and Molecular Mechanisms of Bone Remodeling. 2010;285(33):25103-8.

17. Swanson CM, Shea SA, Ph D, Stone KL, Ph D, Jane A, et al. Obstructive Sleep Apnea and Metabolic Bone Disease: Insights In To The Relationship Between Bone and Sleep. 2016;30(2):199-211.

18. Marques EA, Figueiredo P, Sigurdsson S, Aspelund T, Siggeirsdottir K. Measurements of Muscle 


\section{ISSN 25980580}

and Bone : the AGES-Reykjavik Study. 2017;(301):1-6.

19. Evans AL, Paggiosi MA, Eastell R, Walsh JS. Bone Density, Microstructure and Strength in. J Bone Miner Res. 2015;30(5).

20. Gallagher JC. Vitamin D and Aging. 2014;25:1-18.

21. Nguyen T V, Sambrook PN, Eisman JA. Bone Loss, Physical Activity, and Weight Change. J Bone Miner Res. 1998;13.

22. Mcmillan LB. Prescribing Physical Activity for the Prevention and Treatment of Osteoporosis in Older Adults. Healthcare. 2017;1-15.

23. Jackuliak P, Payer J. Osteoporosis , Fractures , and Diabetes. 2014;2014.

24. Sundararaghavan V, Mazur MM, Evans B, Liu J, Ebraheim NA. Diabetes and bone health : latest evidence and clinical implications. 2017;67-74. 
ISSN 25980580 